\title{
Plasma viscosity or erythrocyte sedimentation rate in the diagnosis of giant cell arteritis?
}

\author{
G P H Brittain, G G McIlwaine, J A Bell, J M Gibson
}

\begin{abstract}
Plasma viscosity (PV) has replaced the erythrocyte sedimentation rate (ESR) as a routine laboratory test in many hospitals. The finding of a normal PV but raised ESR in a case of biopsy proved giant cell arteritis (GCA) cast doubt on this substitution in cases of suspected GCA. To assess the equivalence of PV and ESR in the diagnosis of this disease 40 suspected cases were prospectively investigated with both tests. The correlation between the two tests was good $(r=0.742, p<0.0001)$. The substitution of one test for the other would appear to be justified in most cases of suspected GCA. In the presence of biopsy proved disease, however, the PV and ESR each produced $13 \cdot 3 \%$ false negatives. These occurred both in combination with and independently of the other test showing that, when in error, the two tests may not be equivalent. In cases of doubt the performing of both PV and ESR tests together improves but does not achieve complete diagnostic accuracy. Clinical judgment based on careful assessment of all available symptoms and signs must remain the foundation of diagnosis.
\end{abstract}

The diagnosis of giant cell arteritis (GCA) and the decision to perform artery biopsy often depends on finding a raised plasma viscosity (PV) or erythrocyte sedimentation rate (ESR). Many hospital laboratories have adopted automated measurement of PV in preference to ESR as a routine investigation. The justification for this substitution is that a close linear correlation between PV and ESR in health and in the presence of infectious, malignant, and other non-arteritic disease has been shown. ${ }^{1-3}$ There are advantages for the laboratory in measuring plasma viscosity instead of the ESR, but to our knowledge there is no direct evidence that plasma viscosity may be substituted for ESR in the diagnosis of GCA.

The stimulus for this study was the finding of a normal plasma viscosity in a patient with a strong clinical history of GCA. The ESR, however, was found to be significantly raised, and temporal artery biopsy then confirmed the presence of GCA. These findings questioned the substitution of plasma viscosity for ESR in the routine investigation of GCA, and to clarify this situation suspected cases of this disease were prospectively investigated by both plasma viscosity and ESR.

\section{Material and methods}

Patients suspected of having giant cell arteritis were randomly entered into the study over a 54- month period. A general medical and ophthalmic history and physical examination was performed on each.

To assess the degree of severity of the clinical findings 'Symptom points' were allotted to each patient in the following way:

\section{Indicators awarded two symptom points}

Temporal pain and tenderness.

Abnormal temporal vessels on palpation.

Scalp necrosis.

Tongue or jaw claudication.

Shoulder girdle/proximal muscle pain and stiffness.

\section{Indicators awarded one symptom point}

Headache.

Visual loss.

Amaurosis fugax or transient visual blurring.

Altitudinal field defect.

Anterior ischaemic optic neuropathy or cotton-wool spots.

Central retinal artery occlusion.

Ophthalmoplegia, diplopia, or ptosis.

Recent onset of heart failure or myocardial infarction.

Fatige, Malaise, anorexia, or weight loss.

Fever of unknown origin.

Anaemia.

Before beginning steroid therapy we collected separate samples of venous blood in potassium EDTA for measuring the ESR, PV, and full blood count. Both ESR and PV were measured only if there was a strong intention to perform a temporal artery biopsy. The ESR was measured by the Westergren method ${ }^{4}$ and PV by the automated Coulter method..$^{56}$ Normal ranges of PV assumed for this study (see below) were $1.5-$ $1.72 \mathrm{cP}$ and ESR $<20 \mathrm{~mm} / \mathrm{h}$ for men and $25 \mathrm{~mm} /$ $h$ for women. Where clinical evidence of GCA was strong, steroid therapy was begun and biopsy was performed within 24 hours. A single temporal artery biopsy was performed under lignocaine hydrochloride $2 \%$ with adrenaline tartrate 1: 200000 local anaesthetic, and the specimen of superficial temporal artery underwent histopathological examination.

The clinical and symptomatic response to treatment with systemic steroids was recorded during the few days of inpatient care and at subsequent outpatient attendances.

\section{Results}

A total of 40 patients suspected of having giant cell arteritis were investigated by tests for both PV and ESR, and, of these, 31 underwent temporal artery biopsy. Nine patients were not subjected to biopsy because of insufficient laboratory and clinical support of arteritis. GCA 
Table 1 Results of all biopsied cases of suspected giant cell arteritis

\begin{tabular}{|c|c|c|c|c|c|c|c|c|c|c|c|c|c|}
\hline \multicolumn{7}{|c|}{ Biopsy-positive } & \multicolumn{7}{|c|}{ Biopsy-negative } \\
\hline $\begin{array}{l}\text { Patient } \\
\text { no }\end{array}$ & $\begin{array}{l}P V \\
c P\end{array}$ & $\begin{array}{l}E S R \\
\mathrm{~mm} / \mathrm{h}\end{array}$ & $\begin{array}{l}H b \\
g / d l\end{array}$ & $\begin{array}{l}\text { Age } \\
y r\end{array}$ & Sex & $\begin{array}{l}\text { Symptom } \\
\text { points }\end{array}$ & $\begin{array}{l}\text { Patient } \\
\text { no }\end{array}$ & $\begin{array}{l}P V \\
c P\end{array}$ & $\begin{array}{l}E S R \\
\mathrm{~mm} / \mathrm{h}\end{array}$ & $\begin{array}{l}H b \\
g / d l\end{array}$ & $\begin{array}{l}\text { Age } \\
y r\end{array}$ & Sex & $\begin{array}{l}\text { Symptom } \\
\text { points }\end{array}$ \\
\hline $\begin{array}{r}1 \\
2 \\
3 \\
4 \\
5 \\
6 \\
7 \\
8 \\
9 \\
10 \\
11 \\
12 \\
13 \\
14 \\
15\end{array}$ & $\begin{array}{l}1 \cdot 73 \dagger \\
1.98 \\
2.01 \\
1.92 \\
2.26 \\
2.02 \\
1.75 \dagger \\
2.78 \\
1.98 \\
2 \cdot 19 \\
2.34 \\
2.55 \\
2.34 \\
2.35 \\
1.94\end{array}$ & $\begin{array}{c}60 \\
89 \\
89 \\
93 \\
119 \\
83 \\
19 \dagger \\
103 \\
102 \\
106 \\
116 \\
131 \\
7 \dagger \\
120 \\
66\end{array}$ & $\begin{array}{r}13 \cdot 0 \\
11 \cdot 3 \\
12 \cdot 3 \\
6 \cdot 8 \\
10 \cdot 4 \\
12 \cdot 9 \\
14 \cdot 2 \\
13 \cdot 9 \\
12 \cdot 2 \\
11 \cdot 1 \\
11 \cdot 6 \\
9 \cdot 2 \\
7 \cdot 8 \\
10.9 \\
12 \cdot 4\end{array}$ & $\begin{array}{l}83 \\
79 \\
64 \\
78 \\
71 \\
82 \\
74 \\
76 \\
75 \\
85 \\
77 \\
74 \\
80 \\
78 \\
72\end{array}$ & $\begin{array}{l}F \\
F \\
F \\
M \\
F \\
F \\
F \\
F \\
M \\
F \\
F \\
F \\
F \\
F \\
F\end{array}$ & $\begin{array}{r}13 \\
8 \\
5 \\
9 \\
10 \\
11 \\
15 \\
11 \\
8 \\
7 \\
11 \\
15 \\
6 \\
7 \\
11\end{array}$ & $\begin{array}{l}16 \dagger \\
17 \dagger \\
18 \\
19 \\
20 \\
21 \\
22 \\
23 \\
24 \\
25 \\
26 \\
27 \\
28 \\
29 \\
30 \\
31\end{array}$ & $\begin{array}{l}2.12 \\
1.92 \\
1.90 \\
1.70 \\
1.58 \\
1.87 \\
1.87 \\
1.85 \\
1.66 \\
1.89 \\
1.80 \\
1.92 \\
1.83 \\
1.84 \\
1.81 \\
1.87\end{array}$ & $\begin{array}{l}52 \\
60 \\
48 \\
17 \\
7 \\
32 \\
14 \\
46 \\
15 \\
80 \\
26 \\
59 \\
32 \\
27 \\
15 \\
41\end{array}$ & $\begin{array}{l}10 \cdot 2 \\
12.6 \\
11.9 \\
14 \cdot 1 \\
15.0 \\
14 \cdot 8 \\
15 \cdot 7 \\
13.9 \\
13 \cdot 7 \\
12 \cdot 4 \\
15 \cdot 2 \\
13.7 \\
14 \cdot 4 \\
14.3 \\
14.6 \\
13 \cdot 1\end{array}$ & $\begin{array}{l}82 \\
89 \\
76 \\
70 \\
72 \\
85 \\
77 \\
74 \\
80 \\
68 \\
72 \\
72 \\
60 \\
71 \\
76 \\
78\end{array}$ & $\begin{array}{l}F \\
F \\
F \\
M \\
M \\
F \\
F \\
M \\
F \\
F \\
M \\
F \\
F \\
F \\
F \\
F\end{array}$ & $\begin{array}{l}8 \\
7 \\
5 \\
3 \\
4 \\
2 \\
2 \\
3 \\
6 \\
4 \\
5 \\
4 \\
7 \\
3 \\
3 \\
7\end{array}$ \\
\hline Average & $2 \cdot 14$ & $86 \cdot 9$ & $11 \cdot 3$ & $76 \cdot 5$ & & $9 \cdot 8$ & & $1 \cdot 84$ & $35 \cdot 7$ & $13 \cdot 7$ & $75 \cdot 1$ & & $4 \cdot 7$ \\
\hline
\end{tabular}

* See text. †False negative result. Cases 16 and 17 suspected false negative biopsies.

was histologically confirmed in $15(48 \cdot 4 \%)$ of the 31 biopsy specimens. Definite histological proof of giant cell arteritis was missing in the remaining 16 cases (Table 1 ).

The ESR was plotted against PV for all 40 of cases of suspected giant cell arteritis (Fig 1). Good correlation between ESR and plasma viscosity was found, the coefficient for all cases being $0.74(p<0.0001)$. The coefficient between PV and ESR for the 15 biopsy-positive cases was $0.46(p=0.082)$, but when patient 13 with a low ESR related to aspirin consumption was excluded the coefficient for the biopsy positive group became $0.74(p=0.0024)$, matching that for all 40 cases.

The symptom profile in the biopsy-negative group was less severe (average $4 \cdot 7$ symptom points) than in the biopsy-positive group (average 9.8 points). However, high scores in the biopsynegative group cast considerable doubt on the biopsy results. Clinical and laboratory evidence of arteritis was so strong in cases 16 and 17 that the biopsies were taken as false negative, and steroid treatment was continued regardless. In other cases steroids were gradually tailed off according to symptoms.

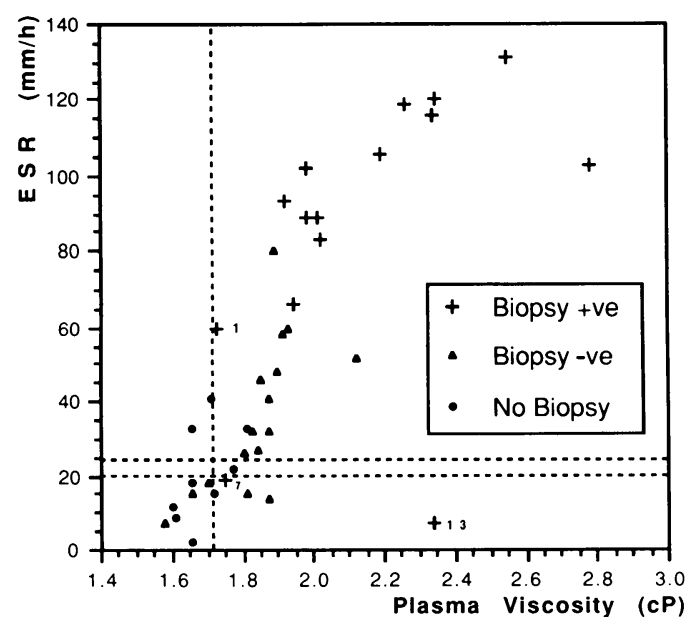

Figure 1 Plasma viscosity plotted against ESR, with upper limits of normal shown (see text). False negative cases are numbered.
Of the 15 biopsy proved cases only two were male. The right eye was first affected in 10 patients. One female presented with profound bilateral visual loss, both eyes being affected within a few hours of the onset of visual symptoms, her vision was reduced to counting fingers and no light perception in the right and left eyes respectively. Seven cases presented with visual field loss (lower altitudinal field loss in six cases). Transient episodes of blurring or darkening of vision were reported up to two weeks prior to onset of severe visual loss in four cases. The extraocular muscles were affected in three cases. One presented as a painful, pupil-sparing, partial third nerve palsy with ptosis without visual loss, while visual loss was associated with ptosis in one case and preceded by diplopia for two days in another. There were two cases with scalp necrosis resulting from temporal artery occlusion. Superficial temporal vessels were pulsatile, not tender, and normal to palpation in five cases (33\%).

A normocytic or mildly microcytic hypochromic anaemia was found in eight $(53 \%)$ of the biopsy positive cases but in only one $(6 \%)$ of the biopsy negative group, case 16 , which was a suspected false negative biopsy.

\section{BIOPSY-POSITIVE CASES WITH FALSE NEGATIVE} LABORATORY RESULTS

Patient 1 , with a normal PV, was suffering from Paget's disease of bone and taking etidronate disodium $200 \mathrm{mg}$ daily, thyroxine $0.5 \mathrm{mg}$ daily, and occasional paracetamol tablets, but no other medications. She had a normal full blood count. Patient 13, had been taking high doses of aspirin for many days for muscle pains. Her low ESR and microcytic hypochromic anaemia may have been related to this. Her plasma fibrinogen was raised at $10 \cdot 3 \mathrm{~g} / 1$ (normal $2-4 \mathrm{~g} / \mathrm{l}$ ). Patient 7 was taking warfarin $5 \mathrm{mg} /$ day to maintain an axillobifemoral bypass. She had a normal plasma fibrinogen, red cell count, and red cell morphology. 
oral prednisolone (40-100 $\mathrm{mg} /$ day) the plasma viscosity returned to $1.78 \mathrm{cP}$ or less within an average of eight days (range 4-14 days), with the exception of case 8 , in which it remained raised for eight months despite adequate control of symptoms. Temperature returned to normal within 24 hours in the four cases with mild pyrexia. Relief from muscle pains and headache was noted within three days in eight of the biopsy-positive group and in both the suspected false negative cases and in cases 24 and 31 .

The patient recovered from the partial third nerve palsy in six days. There was recovery of vision from $6 / 36$ to $6 / 9$ in two cases and from counting fingers at $1 \mathrm{~m}$ to $6 / 12$ in another, taking three days, six days, and two months respectively. These three patients had all suffered lower altitudinal field loss preceded by 3-14 days of intermittent visual disturbances; all were left with reduced visual fields. The remaining 11 cases of visual loss, including the case of bilateral loss, had no useful recovery of vision. Case 11, who presented with a central retinal artery occlusion, died from a cerebrovascular lesion 10 days after starting systemic steroids. In the biopsy-negative group case 24 died of a myocardial infarction 18 days after her biopsy while still taking prednisolone $20 \mathrm{mg}$ daily.

\section{Discussion}

The reported average annual incidence of GCA in the white population aged over 50 years is approximately 12 per 100000 and more than three times this in females of over 70 years. ${ }^{7}$ The disease is not confined to whites or to those over the age of $50 .^{8-10}$ Histological evidence of GCA has been found in 5\% of randomly selected necropsy cases of people over 60 who died from non-arteritic disease, and the incidence of the disease is probably much higher than reported. ${ }^{1}$ With an increasing elderly population GCA is likely to be more frequently encountered.

A raised ESR has been central to the diagnosis of GCA. The test is cheap and requires no sophisticated equipment but has several disadvantages. It is not popular with laboratory staff because it is time-consuming and the technician must first set up the test and then return later to record the result. Blood must be used within two hours of venepuncture, ${ }^{12}$ so individual routine tests must be performed as they present rather than stored for batch testing. The test requires a certain amount of handling of blood, with all the associated risks. The range of normal for ESR varies between laboratories and is poorly defined, as it is affected by many factors such as age, sex, drugs, red cell morphology, and cell count. ${ }^{12-15}$ We experienced difficulty in arriving at a definitive upper limit of normal for the age group in our study. Suggested upper limits in the over 60 age group range from $14 \mathrm{~mm} / \mathrm{h}$ and $20 \mathrm{~mm} / \mathrm{h}$ in men and women respectively, ${ }^{16}$ up to $40 \mathrm{~mm} / \mathrm{h}$ or even $60 \mathrm{~mm} / \mathrm{h}$ in cases of anaemia. ${ }^{13}$ For the purpose of our study we took the limits to be $20 \mathrm{~mm} / \mathrm{h}$ for men and $25 \mathrm{~mm} / \mathrm{h}$ for women.

A normal ESR in association with GCA, as occurred in two (13\%) of our biopsy proved cases, has been reported. ${ }^{17-19}$ One of these (case
13) had been taking frequent doses of aspirin. The use of anti-inflammatory agents can rapidly reduce the ESR to within normal levels, while the PV may take many days to fall to normal levels. ${ }^{5}$ The aches and pains associated with GCA make aspirin consumptions a likely feature of the disease which must be looked for in the drug history; if it is found, a low ESR must be interpreted with caution, and a supplementary PV test should be performed.

Many laboratories have turned to automated measurement of PV as a substitute for the ESR. The automated test requires a larger initial capital expenditure but thereafter is inexpensive, convenient and quick, and can be performed in batches of small volumes of stored blood with minimal handling. ${ }^{256}$ Plasma viscosity is independent of factors such as age, sex, and haematocrit, and unlike the ESR it has a narrow normal range with well defined upper and lower limits' which vary little over many years in an individual, and a change as small as $0.05 \mathrm{cP}$ may be of significance. ${ }^{20}$ Despite this we found similar false negative rates in both PV and ESR.

Alternative blood tests to diagnose and monitor giant cell arteritis have been proposed, but none has yet stood out as a substitute for either PV or ESR, though there is some support for the use of C-reactive protein level as an adjunct to the ESR as a measure of the acute phase response. ${ }^{101721}$

Mild normochromic or slightly hypochromic anaemia, a common finding in association with GCA, ${ }^{1422-25}$ was found in over half of our biopsypositive cases was rare in the biopsy-negative group. Severe anaemia can raise the ESR and obscure the diagnosis, ${ }^{414}$ but mild degrees of anaemia, in association with other evidence, should increase the level of suspicion of GCA. Suspicion must not be abandoned on finding clinically normal temporal vessels. In agreement with other studies ${ }^{26-28}$ we found that temporal vessels in $33 \%$ of our biopsy proved cases were normal to palpation.

A definite diagnosis of GCA is reached only with a positive biopsy, though the high symptom point score of patients in this group suggests that a diagnosis might have been reached on a clinical grounds alone. Because a negative finding on biopsy does not exclude the disease, ${ }^{29}$ a major diagnostic problem remains with the group of patients in whom biopsy confirmation is not forthcoming and suspicion persists. Repeat biopsy may produce a positive result, but the chance of obtaining a positive specimen is reduced because the patient will probably by this time have been taking steroids for a few days. Case 17 had been started on a low dose of steroids two weeks before presenting to the Eye Department and the biopsy result was considered to be false negative. We have, however, obtained a positive biopsy finding after nine days of steroid treatment from a patient outside this study.

When biopsy fails to confirm suspicions, a careful review of all relevant data must be made. The failure to find a particular feature or positive laboratory result must not be used to rule out the disease, but even weak positive findings which may not be unique to the disease, such as a marked symptomatic improvement on beginning 
steroids; all contribute to and strengthen the final diagnosis. If the biopsy specimen is negative and laboratory results are not far removed from normal and the index of suspicion is low, highdose steroids should be reduced and then gradually tailed off, with a close watch being kept on the patient's symptoms.

Control of GCA by systemic steroids ${ }^{30}$ should be monitored by symptoms rather than by the ESR or plasma viscosity. ${ }^{31}$ Relapses are more likely within the first 18 months of treatment than later, and there is evidence to suggest that systemic steroids should be continued in all cases for at least two years. Most patients should be able to stop treatment after four to five years, though some may need to continue to take a maintenance dose of $2-3 \mathrm{mg}$ of prednisolone indefinitely. ${ }^{31}{ }^{32}$ One report suggests that as many as one-third of patients with predominantly visual or neurological symptoms related to GCA may need life-long therapy.$^{33}$ Once treatment has been stopped, the patient should be warned that it may need to be urgently started again, since arteritic symptoms may return. ${ }^{32}$

Though a sight threatening disease, GCA in isolation does not increase mortality. In our group of 31 biopsied patients, all of which had been started on high-dose steroids, two deaths occurred while steroids were being reduced, adding weight to the report that mortality is increased in GCA in association with steroid treatment. ${ }^{33}$ The acute and long term effects of both treating with and withholding steroids in GCA demand that a firm diagnosis is reached. Only a positive artery biopsy can provide this with certainty. Before biopsy is performed a strong presumptive diagnosis must be reached, and this may be missed if too much reliance is placed on any single clinical feature or laboratory result.

\section{CONCLUSIONS}

The performance of biopsy in suspected cases of GCA often depends on the finding of raised PV or ESR, but either test can be normal in the presence of active disease. Both tests have similar false-negative rates, and in our study one test did not appear to be more accurate than the other. There was a close correlation between the two tests, and on this basis the routine substitution of PV for ESR in the diagnosis of giant cell arteritis would appear to be justified. However, a falsenegative result can occur in either test when the other is positive, and it may be helpful to perform both tests together where a clinical suspicion exists which is not supported by one test alone. The decision to biopsy should never be made on an isolated symptom, sign, or laboratory result but must follow careful consideration of all available information.

We thank the consulting ophthalmologists at the Leicester Roya Infirmary for permission to report the findings on their patients, and Dr V E Mitchell, consultant haematologist, and Mrs B Allen, chief MLSO, and other members of the Leicester Royal Infirmary Haematology department for their assistance with this study.

1 Bradlow BA, Haggan JM. A comparison of the plasma viscosity and the erythrocyte sedimentation rate as screening tests. S Afr Med F 1979; 55: 415-20.

2 Hutchinson RM, Eastham RD. A comparison of the erythrocyte sedimentation rate and plasma viscosity in detecting cyte sedimentation rate and plasma viscosity in detecting
changes in plasma proteins. $\mathcal{F}$ Clin Pathol 1977 ; 30: 345-9.

3 Thomas J. Plasma viscosity as a routine laboratory test. $\mathcal{F}$ Clin Pathol 1978; 31: 293-4.

4 Westergren A. Studies of the suspension stability of the blood in pulmonary tuberculosis. Acta Med Scand 1921; 54: 24782.

5 Harkness J. The viscosity of human blood plasma; its measurement in health and disease. Biorheology 1971; 8: 171-93.

6 Cooke BM, Stuart J. Automated measurement of plasma viscosity by capillary viscometer. F Clin Pathol 1988; 41 : viscosity $1213-6$.

7 Hutson KA, Hunder GG, Lie JT, et al. Temporal arteritis: a 25 year epidemiologic, clinical and pathological study. Ann Intern Med 1978; 88: 162-7.

8 Ballou SP, Kalm MA, Kushner I. Giant cell arteritis in a black patient. Ann Intern Med 1978; 88: 659-60.

9 Love DC, Rapkin J, Lesser GR, et al. Temporal arteritis in blacks. Ann Intern Med 1986; 105: 387-9.

10 Hayreh SS. Anterior ischaemic optic neuropathy. Differentiation of arteritic from non-arteritic type and its management. Eye 1990;4: 25-41.

11 Ainsworth RW, Gresham GA, Balmforth GV. Pathological changes in temporal arteries removed from selected cadavers. fhanges in temporal arteries rem Pathol 1961; 14: 115-27.

12 International Committee for Standardisation in Haematology. Recommendation for measurement of erythrocyte sedimentation rate of human blood. Am f Clin Pathol 1977; 68 505-7.

13 Kulvin SM. Erythrocycte sedimentation rates in the elderly. Arch Ophthalmol 1972; 88: 617-8.

14 Jacobsen DM, Slamovits TL. Erythrocyte sedimentation rate and its relationship to haematocrit in giant cell arteritis. Arch Ophthalmol 1987; 105: 965-7.

15 Love DC, Berler DK, O'Dowd GJ, Brooks JZ, Love RA. Erythrocyte sedimentation rate and its relationship to haematocrit in giant cell arteritis. Arch Ophthalmol 1988; 106: haemato.

16 Dacie JV, Lewis SM. Practical haematology. 7th Ed. Edinburgh: Churchill-Livingstone, 1991; 522 .

17 Wong RL, Korn JK. Temporal arteritis without an elevated erythrocyte sedimentation rate. Am F Med 1986; 80: 959-64.

18 Newman P. Giant cell arteritis with normal sedimentation rate. Arch Neurol 1978; 35: 620.

19 Kansu T, Corbett JJ, Savino P, Schatz NJ. Giant cell arteritis with normal sedimentation rate. Arch Neurol 1977; 34: 624 5 .

20 Hall R, Malia RG, Erythrocyte sedimentation rate and plasma viscosity. Medical laboratory haematology. London: Buttervorth, 1984: 182-190.

21 Stuart J, Lewis SM. Monitoring the acute phase response. Alternative tests to measuring erythrocyte sedimentation Alternative tests to measuring eryt
rate. $\mathrm{BrMed} \mathcal{F} 1988 ; 297: 1143-4$.

22 Whitfield AGW, Bateman M, Cooke WT. Temporal arteritis. Brf Ophthalmol 1963; 47: 555-65.

23 Whitaker JJ, Hagerdorn AB, Pease GL. Anaemia in tempora arteritis. Postgrad Med 1966; 40: 35-9.

24 Allison MC, Gough KR. Steroid sensitive systemic disease with anaemia in the elderly: a manifestation of giant cell arteritis? Postgrad Med F 1985; 61: 501-3.

25 Unwin RJ, Carmichael DJ, Peart WS. Severe cardiac failure and leukoerythroblasic anaemia in a patient with giant cell and leukoerythroblasic anaemia in a patis.

26 Hamilton CR Jr, Shelley WM, Tumuly PA. Giant cell arteritis including temporal arteritis and polymyalgia rheumatica. Medicine 1971; 50: 1-27.

27 Bevan AT, Dunhill MS, Harrison MJG. Clinical and biopsy findings in temporal arteritis. Ann Rheum Dis 1968; 27: 271 7.

28 Fauchald P, Rygvold O, Oystese B. Temporal arteritis and polymyalgia rheumatica. Clinical and biopsy findings. Ann Intern Med 1972; 77: 845-52.

29 Albert DM, Ruchman MC, Keltner JL. Skip areas in temporal arteritis. Arch Ophthalmol 1976; 94: 2072-7.

30 Birkhead NC, Wagener HP, Schick RM. Treatment of temporal arteritis with adrenal corticosteroids. Results of 55 temporal arteritis with adrenal corticosteroids. Results of 55 : cases wher

31 Beevers DG, Harpur JE, Turk KAD. Giant cell arteritis - the need for prolonged treatment. F Chronic Dis 1973; 26: 5716.

32 Kyle V, Hazelman BL. Stopping steroids in polymyalgia rheumatica and giant cell arteritis. Br Med F 1990; 300: 344 5.

33 Graham E, Holland A, Avery A, Ross Russell RW. Prognosis in giant cell arteritis. Br Med f 1981; 282: 269-71. 